\title{
Acute haemorrhage secondary to arteriovenous haemodialysis fistula pseudoaneurysm - the challenge of restoring a deformed upper limb
}

\author{
Tal Salamon, ${ }^{1}$ Wajdi Safadi, ${ }^{2,3}$ Alexander Izakson ${ }^{4}$
}

${ }^{1}$ Department of Vascular Surgery, Ziv Hospital, Affiliated to the Faculty of Medicine in the Galilee Bar Ilan University, Safed, Israel

${ }^{2}$ Department of Surgery, Ziv Hospital, Galilee, Israel ${ }^{3}$ Golan Polyclinic, Golan Heights, Israel ${ }^{4}$ Department of Anesthesiology, Ziv Hospital, Affiliated to the Faculty of Medicine in the Galilee Bar Ilan University, Safed, Israel

\section{Correspondence to}

Dr Wajdi Safadi,

golanpolyclinic@gmail.com

Accepted 30 May 2015

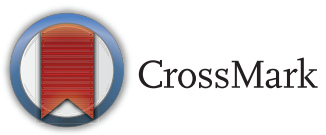

To cite: Salamon $T$, Safadi W, Izakson A. BMJ Case Rep Published online: [please include Day Month Year] doi:10.1136/bcr-2015210243

\section{DESCRIPTION}

A 48-year-old man presented with active bleeding from an infected ulcer overlying a large pseudoaneurysm arising from a 10 -year-old brachiocephalic arteriovenous fistula (AVF) in a grossly swollen and deformed upper limb (figures 1 and 2). The patient had end stage renal disease secondary to polycystic kidney disease and hypertension. At the time of presentation with bleeding, he had intercurrent community acquired pneumonia, treated with cefuroxime $500 \mathrm{mg}$ twice daily. Bleeding was controlled with local pressure. Haemoglobin on admission was $10.2 \mathrm{~g} / \mathrm{dL}$ (it was $12.9 \mathrm{~g} / \mathrm{dL}$ a week earlier). Two months prior, as an elective

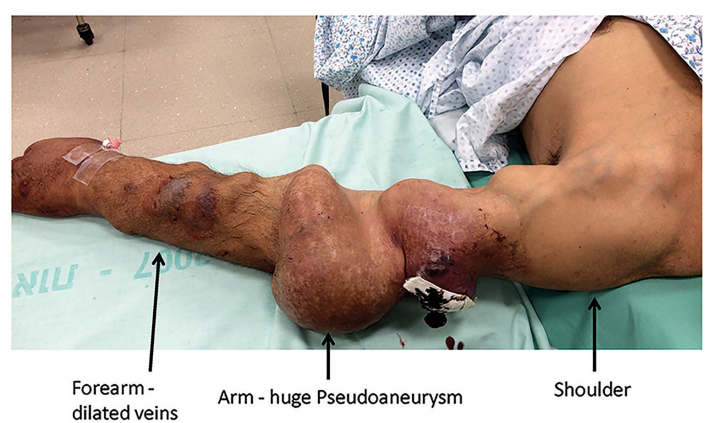

Figure 1 The left arm showing a 10-year-old patent brachiocephalic arteriovenous fistula with distended 'retrograde' veins in the forearm, extending up to the subclavian region. There are two large pseudoaneurysms (each measuring $15 \times 10 \mathrm{~cm}$ ). The ulcerated skin, which was bleeding, is covered with a haemostatic dressing (Surgicel Nu-Knit, Ethicon).

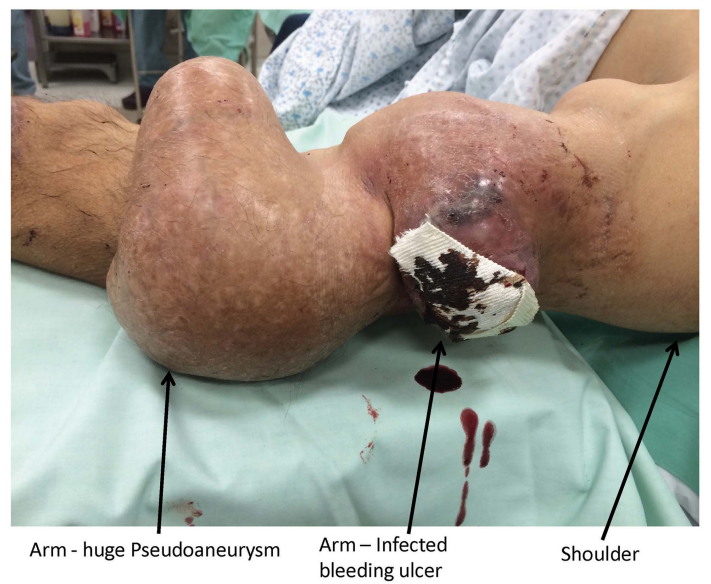

Figure 2 Pseudoaneurysms. The skin ulcer has a necrotic base and has become infected.

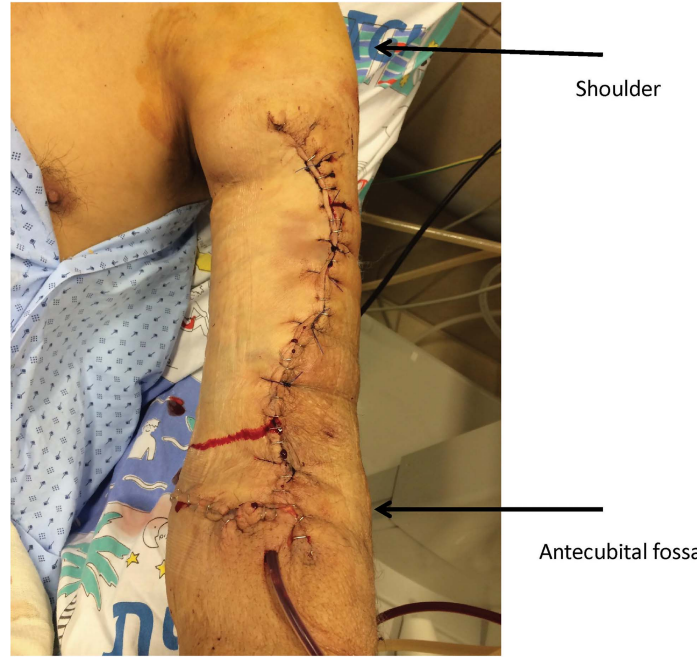

Figure 3 The left arm after resection of the abnormal veins and extra skin. Skin closure was achieved and the skin is viable. Veins in the forearm and shoulder are no longer visible.

procedure, a radiocephalic AVF was constructed on the contralateral wrist in anticipation of rupture of the pseudoaneurysm. ${ }^{12}$

Surgery-ultrasound guided brachial plexus block-was performed under regional anaesthesia. Owing to the size of the vessels, the arm and the ulcer, surgery proceeded with arterial (brachial)

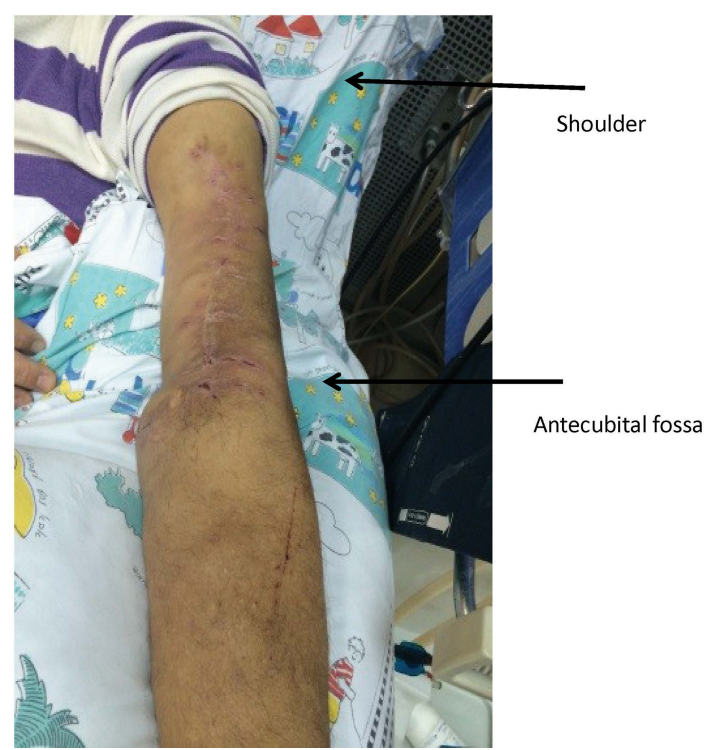

Figure 4 The left arm 6 weeks after surgery. The skin remains viable. 
control in the mid-arm. The enlarged $(2 \mathrm{~cm})$ artery was controlled in a vascular sling. ${ }^{3}$ The skin was incised at the site of the original incision, with careful dissection to the arterialvenous anastomosis. The brachial artery proximal and distal to the anastomosis was controlled and clamped. The vein was incised and separated from the AVF. Arterial closure was achieved with a running $5 / 0$ prolene suture.

\section{Learning points}

In the case of gross distension, proximal arterial control should initially be achieved through the application of a tourniquet, endovascular intra-arterial balloon or an additional upstream incision.

- If skin incisions are large and vascular repair is planned, ultrasound-guided regional anaesthesia is a good option, circumventing the need for general anaesthesia in haemodialysis patients.

- Although rupture of an arteriovenous fistula (AVF) pseudoaneurysm is not common, a second AVF should be reconstructed prior to potential rupture.
Reconstruction of the upper limb involved the excision of a large flap of skin and excision of the infected ulcer. The skin was incised over the medial border of the arm, and the pseudoaneurysm was dissected free. Spare skin, including the ulcer, was excised and primary closure achieved with a 1/0 Prolene suture and skin staples (figure 3). A long drain was inserted on the left and an elastic bandage from fingers-to-shoulder was applied. Postoperatively, the hand was viable. The drain was removed after $24 \mathrm{~h}$. The contours of the arm were significantly reduced and the skin well perfused. Six weeks postoperation, the patient had viable skin, no oedema and normal wound healing (figure 4).

Competing interests None declared.

Patient consent Obtained.

Provenance and peer review Not commissioned; externally peer reviewed.

\section{REFERENCES}

1 Valenti D, Mistry H, Stephenson M. A novel classification system for autogenous arteriovenous fistula aneurysms in renal access patients. Vasc Endovascular Surg 2014;48:491-6.

2 Najibi S, Bush RL, Terremani TT, et al. Covered stent exclusion of dialysis access Pseudoaneurysms. J Surg Res 2002;106:15-19.

3 Georgakarakos El, Kapoulas KC, Georgiadis GS, et al. An overview of the hemodynamic aspects of the blood flow in the venous outflow tract of the arteriovenous fistula. J Vasc Access 2012;13:271-8.

Copyright 2015 BMJ Publishing Group. All rights reserved. For permission to reuse any of this content visit

http://group.bmj.com/group/rights-licensing/permissions.

BMJ Case Report Fellows may re-use this article for personal use and teaching without any further permission.

Become a Fellow of BMJ Case Reports today and you can:

- Submit as many cases as you like

- Enjoy fast sympathetic peer review and rapid publication of accepted articles

- Access all the published articles

- Re-use any of the published material for personal use and teaching without further permission

For information on Institutional Fellowships contact consortiasales@bmjgroup.com

Visit casereports.bmj.com for more articles like this and to become a Fellow 